\title{
Structural and Optical Investigations of Radiation Damage in Transparent PET Polymer Films
}

\author{
Shiv Govind Prasad, ${ }^{1}$ Abhijit De, ${ }^{2}$ and Udayan $\mathrm{De}^{3}$ \\ ${ }^{1}$ Department of Chemistry, Uttar Pradesh Textile Technology Institute, 11/208 Souterganj Kanpur 208001, India \\ ${ }^{2}$ Department of Physics, Presidency College, 86/1 College Street, Kolkata 700 073, India \\ ${ }^{3}$ Variable Energy Cyclotron Centre, 1/AF Bidhannagar, Kolkata 700 064, India
}

Correspondence should be addressed to Udayan De, ude2006@gmail.com

Received 10 November 2010; Accepted 11 February 2011

Academic Editor: Rolf W. Berg

Copyright (C) 2011 Shiv Govind Prasad et al. This is an open access article distributed under the Creative Commons Attribution License, which permits unrestricted use, distribution, and reproduction in any medium, provided the original work is properly cited.

\begin{abstract}
Effects of gamma irradiation at different doses up to $135 \mathrm{kGy}$ on polyethylene terephthalate (PET) polymer films have been investigated by X-ray diffraction (XRD), Fourier transform infrared (FTIR) spectroscopy, and ultraviolet-visible (UV-VIS) spectroscopy. From XRD analysis, it was found that even at a high dose of gamma irradiation of $135 \mathrm{kGy}$, crystallinity of the PET samples remain unchanged. However, the FTIR peak at $871 \mathrm{~cm}^{-1}$ (depicting C-H bending mode of out-of-plane vibration) and another at $1303 \mathrm{~cm}^{-1}$ (representing $\mathrm{C}-\mathrm{H}$ bending mode of in-plane vibration) disappear for gamma-irradiated PET. In this study, it has also been found that $\gamma$-irradiation in air enhances the optical absorption in the wavelength region $320-370 \mathrm{~nm}$. This has been attributed to free radicals being produced in the polymer by the $\gamma$-radiation. Further, the free radicals react with oxygen of air to form carbonyl group and hydroxyls. With increasing $\gamma$-dose, there is a red shift of the UV-near visible cutoff for PET. XRD and FTIR observations on $\gamma$-damage have been correlated.
\end{abstract}

\section{Introduction}

Radiation damage to various polymers [1-12] due to irradiation by either fast ions or energetic neutrons or high energy photons is a topic of practical and theoretical interest. Theoretical effort aims to understand [1-3] topics like the relative contribution of crosslinking and chain scission to the damage and the detailed mechanisms of the damage. The practical interest in such radiation damage pertains to utility factor and various applications. PET or polyethylene terephthalate films have attracted interest as polymers due to their ample application and wide availability. The changes, due to $\mathrm{Mo}, \mathrm{N}, \mathrm{O}$, and $\mathrm{Kr}$ ion irradiations $[4,12]$ in PET structure, have been reported, and correlation of these changes to other properties were attempted. However, many aspects of damages due to $\gamma$-radiation and fast ions are not yet clearly understood so that more experimental data are welcome.

A high energy ion affects nuclei of the target solid in addition to its electronic interaction in the solid, and its energy is very often chosen to be much higher than $\gamma$ photon energy, here, $1.25 \mathrm{MeV}$. Electronic excitation can affect polymer bonding with varied results that depend on both the nature of radiation and the nature of the polymer in a complex manner. Our DSC thermogram $[9,10]$ showed that radiation induced changes of melting point of PEO-salt samples are in opposite directions for $160 \mathrm{MeV}$ $\mathrm{Ne}^{6+}$ ion and $1.25 \mathrm{MeV} \gamma$-ray irradiations. This interesting feature hints at different mechanisms of radiation damage in two cases-chain scission predominating in the $\gamma$-radiation, while $160 \mathrm{MeV} \mathrm{Ne}$ ions must have made crosslinking of chains to be the predominant damage process. Chain scission is known to predominate [11] in $\gamma$-irradiated PET as well. Heavier high energy ions can deposit much higher energy in a lower volume [4], to form ion tracks in polymers, causing different effects. So, damage by each kind of radiation needs to be documented.

FTIR spectroscopy has been one of the most powerful among the qualitative and quantitative methods of studying molecular bonding structure and functional group analysis. 
There are a host of references regarding pure structural analysis namely, silicon, germanium, carbon, oxygen and hydrogen related compounds. However, identifying and analysis of functional groups in a compound structure in a polymer like PET are rather complicated and not fully understood. In this study, we have compared and correlated changes in optical property of PET with some functional groups detected in the material.

Among photons, $\gamma$-radiation is very effective in causing damage. Abou Zeid et al. [5] found $\gamma$-radiation to be more effective than thermal neutrons and electron beam in damaging high density polyethylene. For some space applications and practical situations like sterilization of food, packed in a polymer foil or sheet, damage to the polymers by $\gamma$-irradiation needs to be experimentally studied and understood $[6,7]$. In earlier efforts $[8-11]$, we studied radiation damage in engineering polymers and also in ion conducting polymers like PEO-salt compounds. PET (poly (ethylene terephthalate)) is basically a semicrystalline polyaromatic polymer [12] with the empirical formula $\left(\mathrm{C}_{10} \mathrm{H}_{8} \mathrm{O}_{4}\right)_{n}$ as detailed later. The objective of the present study is to understand gamma irradiation-induced change in molecular structure of PET polymer films, from infrared analysis, and its correlation with the radiation effects on crystallinity and optical property.

\section{Experimental Outline}

Our samples were cut as suitable strips from 100 micron thick PET sheets. Such strips were gamma irradiated in air at room temperature to different doses up to $135 \mathrm{kGy}$, with a $130 \mathrm{rads} / \mathrm{min} \mathrm{Co}^{60}$ gamma source (gamma energy = $1.25 \mathrm{MeV})$. Its dose rate $\left(1.3 \mathrm{~Gy} \mathrm{~min}^{-1}\right)$ was determined with the help of the Frick Dosimeter, taking $\mathrm{G}\left(\mathrm{Fe}^{3+}\right)$ as 15.6. Irradiation was carried out without any further intervention on the above-mentioned PET sample. Irradiated samples have always been preserved in vacuum desiccators.

The X-ray diffraction studies were carried out using Brucker AXS diffractometer at IUCA, New Delhi, India, before and after each irradiation for different $\gamma$-doses. FTIR (Fourier transform infrared) spectroscopy of the samples were recorded in the transmission mode using FTIR (PerkinElmer model RX I) spectrometer. The scans were done in the ratio mode with a resolution of $1 \mathrm{~cm}^{-1}$. The number of scans was maintained at 50 for all samples.

The optical absorption spectra of the polymer films were recorded, at room temperature, before and after each gamma irradiation in the wavelength range $200-800 \mathrm{~nm}$ employing UNICAM UV 500 UV-VIS spectrophotometer.

\section{Results and Discussion}

PET, having a chemical composition of $\mathrm{C}, \mathrm{H}$, and $\mathrm{O}$, can be expected to be highly infrared active. It was, therefore, decided to carry out a careful infrared spectroscopy using a FTIR spectrometer to understand the molecular bonds.
Following [4], its chemical structure is

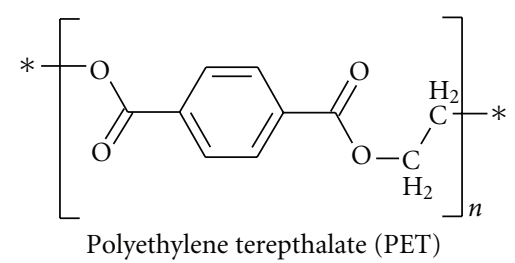

In order to understand the initial crystalline or amorphous nature of the material, XRD results are shown in the consolidated graph of Figure 1. This was done prior to understanding of the molecular bonds in PET. Unirradiated as well as irradiated PET sample depicted only one crystalline peak at $2 \theta=26^{\circ}$ corresponding to (100) plane. With increase of the dose of $\gamma$-irradiation, neither any significant change of the X-ray peaks (like shift in $2 \theta$ of the peak) nor any development of new peaks were observed. This implies that there is no noticeable change, due to $\gamma$-irradiations at least up to $135 \mathrm{kGy}$, of the stacking of the polymer chains. Moreover, no growth of amorphous phase at the expense of the (100) plane crystallinity was detected. This is in contrast to $4.39 \mathrm{MeV} / \mathrm{u} \mathrm{Xe}$ ion irradiation of PET to a fluence of $1.0 \times 10^{12} \mathrm{ions} / \mathrm{cm}^{2}$ (implying an electronic energy loss of $11.4 \mathrm{keV} / \mathrm{nm}$ ) that destroyed the crystallinity, as indicated by (100) plane, completely, and the material finally underwent amorphization [13].

The peaks in FTIR spectra for PET give dual information. Firstly, every peak position is fundamental to molecular bonding structure or functional group existing in the infrared active material. So, any shift in peak position in a spectrum directly refers to a change in bond strength or bond angle. Such a feature is highly probable in a complex structure like PET. This means any change in the network structure of PET directly influence the bonding ( $=\mathrm{CO},-\mathrm{CHO},-\mathrm{OH}$, etc.) of the material. The influence either weakens or strengthens bonding corresponding to a functional group. Weakening and strengthening of a bond shifts the wave number of the corresponding absorption peak to lower and higher values, respectively. Absence of a particular molecular bond relates to scission or break in the particular bonding structure. However, coexistence of various types of functional groups in PET has a combined effect, and, as a result, the infrared absorption peak positions deviate from its pure form. Secondly, variation in intensity of particular peak in a spectrum correlates to the proportion of that functional group present in the material.

Full FTIR spectrum ( 4000 to $450 \mathrm{~cm}^{-1}$ ) for unirradiated PET sample has been shown in Figure 2. FTIR results for all our $\gamma$-irradiated PET samples along with that for the unirradiated sample have been compiled into a composite graph (Figure 3) for easy comparison. In this figure, the FTIR spectra of PET samples with successive gamma irradiations are depicted in the region $2000 \mathrm{~cm}^{-1}$ to $450 \mathrm{~cm}^{-1}$ to focus on the main region of interest only. The usual practice of plotting transmission (in \%), as a function of wavenumber (in $\mathrm{cm}^{-1}$ ), has been followed. The minima or dips in the transmission spectra refer to absorption maxima corresponding to characteristic molecules and groups. 


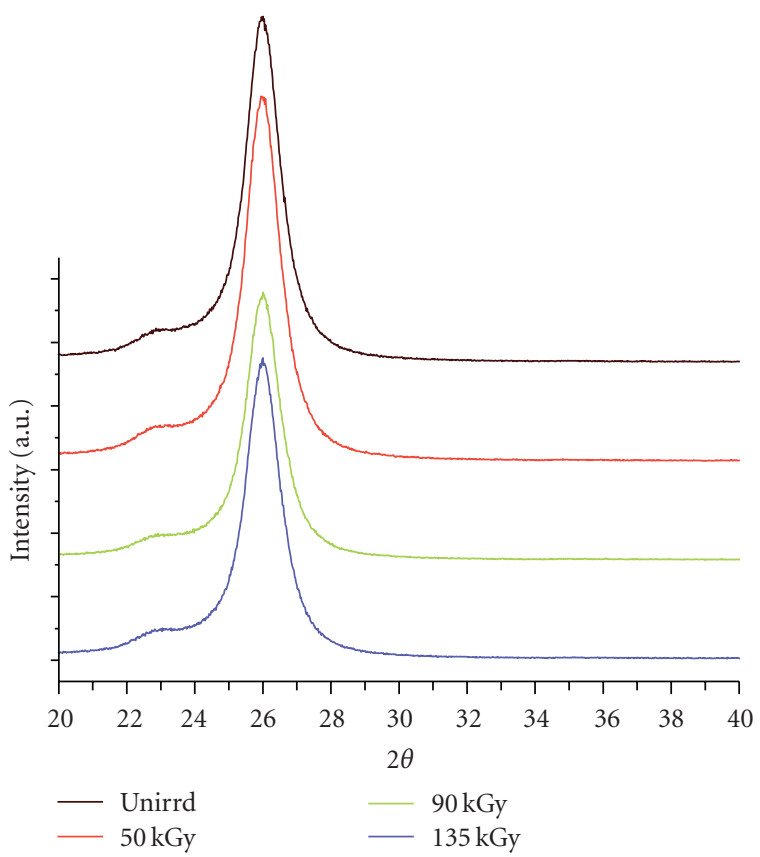

FIGURe 1: X-ray diffraction pattern of PET samples before and after different gamma irradiations as indicated.

In polyethelene terephthalate (PET), there are molecular groups (involving carbon, hydrogen, and oxygen), which are highly infrared active and have characteristic absorption peaks. The FTIR peaks, mostly marked in Figures 2 and 3 , appear in the present infrared absorption spectrum, reflecting their bond strength as outlined next. The C$\mathrm{H}$ stretching modes of vibration are most strong, involve carbon and hydrogen atoms, and show up at higher wavenumbers in different functional groups. These refer to functional groups such as alkyl, alkanal, alkyn, alken, and arene, which appear as absorption peaks in the region 3000$2700 \mathrm{~cm}^{-1}$. The $\mathrm{C}-\mathrm{H}$ bending mode of vibration has weaker bond strength compared to their stretching modes. Such modes of vibration exist in the alkyl and alkene groups. These appear in the absorption spectra in the region 1460$1370 \mathrm{~cm}^{-1}$ and $990-890 \mathrm{~cm}^{-1}$, respectively. In arene, the $\mathrm{C}-\mathrm{H}$ bending mode of vibration, both in plane and out of plane, exist in the region $1300-1000 \mathrm{~cm}^{-1}$ and 900 $650 \mathrm{~cm}^{-1}$, respectively. The $\mathrm{O}-\mathrm{H}$ stretching mode in alkanol $(\mathrm{OH})$ and alkyl groups $\left(\mathrm{CH}_{3}, \mathrm{CH}_{2}\right.$, and $\left.\mathrm{CH}\right)$ exist in the infrared absorption spectra in the region $3650-3590 \mathrm{~cm}^{-1}$. The $\mathrm{C}=\mathrm{O}$ stretching mode of vibration in aliphatic ketone or alkanal, aromatic ketone, alkanoic acid alkanoyl chloride, and alkanoate ester appears in the region $1815-1680 \mathrm{~cm}^{-1}$. Characteristic infrared spectra in the range $1720-1712 \mathrm{~cm}^{-1}$ correspond to $\mathrm{C}=\mathrm{O}$ in the carbonyl group $[14,15]$. The $\mathrm{C}-\mathrm{O}$ stretching modes in alkanoate ester and alkoxy ether have characteristic peaks in the region $1300-1050 \mathrm{~cm}^{-1}$. The groups parasubstituted phenyl ring, ethylene glycol or transconfiguration $\delta\left(\mathrm{CH}_{2}\right), \mathrm{C}=\mathrm{C}$ stretch of phenyl ring and $\mathrm{H}$ vibration attached to phenyl ring- $\delta(\mathrm{CH})$ correspond to $1507,1472,1247$, and $1018 \mathrm{~cm}^{-1}$, respectively. In ethylene

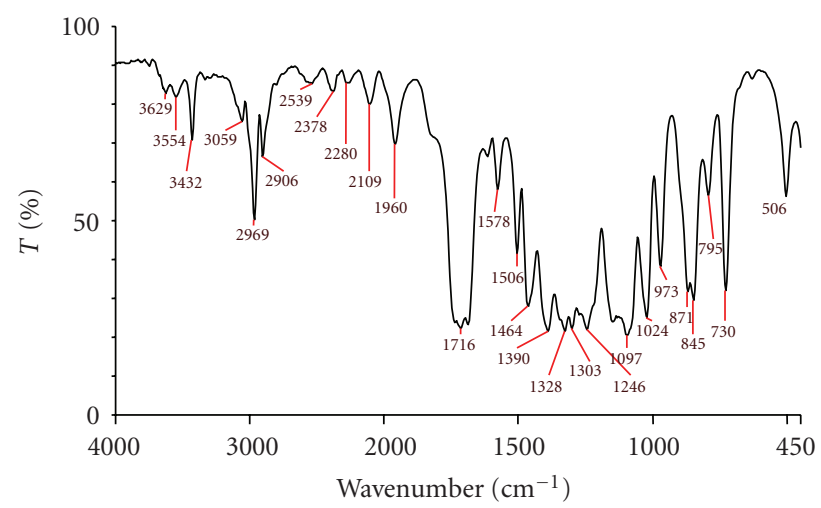

FIgURE 2: FTIR spectrum of unirradiated PET sample showing transmittance $(T \%)$ as a function of wavenumber $\left(\mathrm{cm}^{-1}\right)$ for the range $4000-450 \mathrm{~cm}^{-1}$.

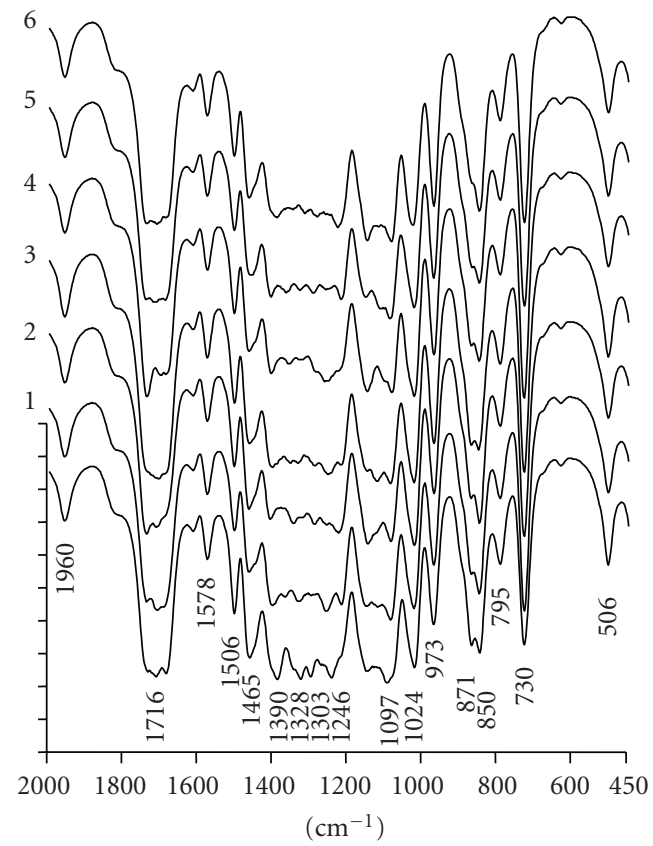

FIgURE 3: FTIR spectra of unirradiated PET sample and of PET samples irradiated to various $\gamma$-irradiation doses: (1) $30 \mathrm{kGy},(2)$ $50 \mathrm{kGy}$, (3) $70 \mathrm{kGy}$, (4) $90 \mathrm{kGy,} \mathrm{(5)} 100 \mathrm{kGy}$, and (6) $135 \mathrm{kGy}$. It shows transmittance $(T \%)$ as a function of wavenumber $\left(\mathrm{cm}^{-1}\right)$.

glycol, transconfiguration- $\nu(\mathrm{CO})$ and $-\nu\left(\mathrm{CH}_{2}\right)$ has signature absorption peaks at 973 and $850 \mathrm{~cm}^{-1}$, respectively. The absorption peak at $873 \mathrm{~cm}^{-1}$ designates $\mathrm{H}$ vibration attached to phenyl ring- $\nu(\mathrm{CH})[15]$.

Steckenreiter et al. reported oxidative degradation of PET in the region $3600-2800 \mathrm{~cm}^{-1}$ for samples irradiated with Mo ions in oxygen atmosphere. They observed C$\mathrm{H}$ and $\mathrm{O}-\mathrm{H}$ stretching vibration of different types of $\mathrm{H}$ bonds and alkyne group $\left(3294 \mathrm{~cm}^{-1}\right)$ in the region 3600 $2500 \mathrm{~cm}^{-1}$. The wagging vibrations for aliphatic, olefinic, aromatic, and acetylenic $\mathrm{CH}$ groups were related to features in the range $1000-650 \mathrm{~cm}^{-1}$. In the aromatic rings, stretching vibrations of double bonds and $\mathrm{CH}_{2}$ bending vibration 
were linked to $1680-1430 \mathrm{~cm}^{-1}$ [4]. The creation of alkynes was assigned to ion irradiation leading to formation of C$\mathrm{H}$ stretching mode of the alkyne end group $(\mathrm{R}-\mathrm{C} \equiv \mathrm{C}-\mathrm{H})$ at $3294 \mathrm{~cm}^{-1}$. The $\mathrm{C} \equiv \mathrm{C}$ stretching vibration was ascribed to $2102 \mathrm{~cm}^{-1}$. The crystalline structure of PET underwent amorphization and was attributed to transconfiguration of the ethylene glycol residue. It was stressed that alkynes were formed near ion trajectory in the ion irradiated PET samples. The aromatic rings underwent a modification from disubstituted to monosubstituted benzene groups rather than getting destroyed. The formation of olefins, carboxylic acids, alcohols and carbon dioxide occurred when PET was subjected to electron or UV irradiation [16, 17]. Main chain scission and formation of olefins in a PET monomer led to degradation products and resulted in products such as benzoic acid residue, alcohols and alkynes. The 1614, 1504, $4101126,1109,1018$, and $875 \mathrm{~cm}^{-1}$ peaks were ascribed to parasubstituted benzene rings, while mono-substituted benzene rings corresponded to 1606 and $713 \mathrm{~cm}^{-1}$. Different mechanisms for ion-induced degradation of polymers under vacuum and in oxygen atmosphere were discussed. Vacuum irradiation resulted in formation of carboxylic acid and benzoic acid residues. On the basis of fast recombination processes of radicals, it was reasoned that the reactions favored formation of alkynes. Further, multiple radicals on the ethylene glycol residue greatly enhanced the probability for creation of alkynes. Such a phenomenon was observed for ion irradiation of PET under vacuum. However, there are reports for absence of alkynes under low ionizing radiation (e.g., gamma, electrons $[18,19]$, or X-rays [20$22])$. Moreover, alkynes were also detected in polymers with aliphatic main chains such as poly (vinylidene fluoride), polyethylene, and polysterene under ion irradiation above a critical energy deposition. It was also concluded that the formation of alkynes required a remarkable reorganization of molecular bonds and assumed that the formation process was strongly related to multiple excitation and ionization events on an extremely short space and time scale.

Dworecki et al. subjected PET samples to $\mathrm{N}^{4+}, \mathrm{O}^{5+}$ and $\mathrm{Kr}^{9+}$ ion irradiation. The energy dissipation by ions in the samples caused damage which was attributed to crosslinking of unsaturated adjacent radicals, amorphization of the crystalline fraction of the polymer, scission of the chains, and oxidation [12]. They observed changes of infrared absorption bands for the methylene group in 3914$2970 \mathrm{~cm}^{-1}, 1683-1578 \mathrm{~cm}^{-1}$, and $631-506 \mathrm{~cm}^{-1}$ regions [12, 23]. The variation of the absorption spectra in the regions $1740-1660 \mathrm{~cm}^{-1}$ and $1660-1600 \mathrm{~cm}^{-1}$ were assigned to the bands of the carbonyl group [12].

Our $\gamma$-irradiation on PET samples did not induce any significant change in the existing $\mathrm{C}-\mathrm{H}$ and $\mathrm{O}-\mathrm{H}$ stretching vibration of different types of $\mathrm{H}$-bonds in the PET and also no alkyne group $\left(3294 \mathrm{~cm}^{-1}\right)$ was detected in the region $3600-2500 \mathrm{~cm}^{-1}$. This is in contrast to the effect of $\mathrm{Kr}$ or Mo ion irradiation of PET [4], but in line with earlier reports of no alkyne group formation in $\gamma$-irradiations of PET. Further, the absorption maxima in regions $\sim 3000 \mathrm{~cm}^{-1}$ to $\sim 1400 \mathrm{~cm}^{-1}$ and $\sim 850 \mathrm{~cm}^{-1}$ to $\sim 500 \mathrm{~cm}^{-1}$ remained practically invariant with increasing $\gamma$-irradiation dose. The region from $\sim 3000 \mathrm{~cm}^{-1}$ to about $2000 \mathrm{~cm}^{-1}$ is attributed to $\mathrm{OH}$ bond which in turn, categorically depends on hydrogenbonding configuration $[14,15,24-26]$. This means that hydroxyl group bonding configuration in the polymer chain remains almost intact under the influence of different doses of $\gamma$-irradiation. As a result the hydroxyl group content remains almost unchanged with increase in chain length of the polymer. The FTIR absorption peak at $1716 \mathrm{~cm}^{-1}$, representing carbonyl $\mathrm{C}=\mathrm{O}$ stretching, is one of the strongest absorption peaks of the FTIR spectra. This peak does not show any significant change in peak intensity or peak position as an effect of $\gamma$-irradiation, the observed changes being minor and fluctuating. However, absorption peaks in the region $1390-1246 \mathrm{~cm}^{-1}$ underwent some interesting changes (Table 1). For PET samples, commencing with initial $\gamma$-irradiation of $30 \mathrm{kGy}$ till $135 \mathrm{kGy}$, the absorption peak shifted from $1097 \mathrm{~cm}^{-1}$ to lower value $1089-1085 \mathrm{~cm}^{-1}$. The $\mathrm{C}=\mathrm{C}$ bond stretching mode at $1246 \mathrm{~cm}^{-1}$ shifted to lower wavenumber $1226 \sim 1150 \mathrm{~cm}^{-1}$ with increasing doses of gamma irradiation. The $1303 \mathrm{~cm}^{-1}$ absorption peak in unirradiated PET, disappeared with the lowest dose (30 kGy) of $\gamma$ irradiation (Table 1). The peak at $1260 \mathrm{~cm}^{-1}$ underwent a variation till $1297 \mathrm{~cm}^{-1}$ with increasing doses of $\gamma$ irradiation (Figure 3 ). These features indicate weakening of the $\mathrm{C}=\mathrm{C}$ bonding modes of vibration with increased dose of gamma irradiation. While on the other hand, the C$\mathrm{C}$ alkane $\left(-\mathrm{H}_{2} \mathrm{C}-\mathrm{CH}_{2}-\right)$ bond at $1328 \mathrm{~cm}^{-1}$ and $1390 \mathrm{~cm}^{-1}$ show almost no change with increased dose of gamma irradiation. This could mean that chemical bond strength related to $\mathrm{C}-\mathrm{C}$ and $\mathrm{CH}_{2}$ remains invariant. Absorption peaks at $\sim 1303,1246$, and $1097 \mathrm{~cm}^{-1}$, which refer to in-plane C$\mathrm{H}$ bending bond and $\mathrm{C}-\mathrm{O}$ stretching bonds corresponding to alkoxy (ether) or alkanoate ester groups, shifted to lower wavenumbers. It is rather clear that any shift in peak towards lower wave number value represents weakening of bonds or scission of bonds and peak shifts towards higher values indicate stronger bonds. The exact reasons for such shifts are still not very clear. It is important to observe that under the impact of lowest dose of gamma irradiation, the absorption peaks at 1302 and $871 \mathrm{~cm}^{-1}$, representing out-of-plane $\mathrm{C}-\mathrm{H}$ bending mode, disappear completely.

There are reports which indicate that crystallinity of PET, corresponding to (100) crystallographic plane, correlate with the existence of infrared absorption peak strength at 1472,973 , and $850 \mathrm{~cm}^{-1}$ corresponding to ethylene glycol molecular groups $[13,27]$. From our data (Table 1), we find that in our PET material the absorption peak nearest to $1472 \mathrm{~cm}^{-1}$ is at $1465 \mathrm{~cm}^{-1}$ in unirradiated PET, and it remains almost invariant with variation of gamma-radiation dose. Infrared absorption at $973 \mathrm{~cm}^{-1}$ and $850 \mathrm{~cm}^{-1}$ remains unchanged. It can be suggested that $\mathrm{C}-\mathrm{O}-\mathrm{C}$ and $\gamma-\left(\mathrm{CH}_{2}\right)$ transconfiguration in the PET samples remains intact and does not undergo any change with variation in gamma radiation doses. As a consequence, the crystalline structure of PET remains unchanged with gamma-radiation doses, as found by X-ray crystallography (Figure 1).

The optical absorbance versus wavelength results from our UV-visible absorption experiment is depicted in Figure 4 for different radiation doses in the range $0-135 \mathrm{kGy}$. It can 
TABLE 1: Our observed wavenumber values $\left(\right.$ in $\mathrm{cm}^{-1}$ ) at the FTIR absorption peaks for unirradiated (UI) and differently $\gamma$-irradiated PET samples. In the symbolic names like PET_135, the numbers in the names indicate $\gamma$-doses in kGy unit.

\begin{tabular}{|c|c|c|c|c|c|c|c|}
\hline PET_UI & PET30 & PET50 & PET70 & PET_90 & PET_100 & PET_135 & Suggested bond configuration \\
\hline 507 & 506 & 505 & 506 & 505 & 505 & 505 & \\
\hline 730 & 730 & 731 & 731 & 731 & 730 & 730 & \\
\hline 795 & 795 & 795 & 795 & 795 & 795 & 795 & \\
\hline 850 & 851 & 850 & 853 & 851 & 851 & 850 & Trans config. $\gamma$ - $\left(\mathrm{CH}_{2}\right)$ \\
\hline 871 & & & & & & & Phenyl $\gamma(\mathrm{CH})$ \\
\hline 973 & 973 & 972 & 972 & 973 & 973 & 973 & $\mathrm{C}-\mathrm{O}-\mathrm{C}$ antisymmetric \\
\hline 1024 & 1026 & 1025 & & 1025 & 1024 & 1028 & \\
\hline 1097 & 1088 & 1087 & 1089 & 1085 & 1089 & 1086 & \\
\hline 1246 & 1219 & 1226 & 1125 & 1151 & 1220 & 1150 & $1246 \mathrm{~cm}^{-1} \mathrm{C}=\mathrm{C}$ stretch of phenyl ring \\
\hline 1303 & & & & & & & $1304 \mathrm{~cm}^{-1} \mathrm{CH}_{2}$ wag \\
\hline 1328 & 1336 & 1349 & 1336 & & 1368 & & $\mathrm{C}-\mathrm{C}$ Alkane, $=\mathrm{CH}_{2}$ \\
\hline 1390 & 1406 & 1410 & 1404 & 1407 & 1408 & 1392 & $1390 \mathrm{~cm}^{-1} \mathrm{C}-\mathrm{C}$ deviation \\
\hline 1465 & 1466 & 1466 & 1466 & 1467 & 1458 & 1467 & \\
\hline 1506 & 1505 & 1506 & 1505 & 1506 & 1506 & 1506 & \\
\hline 1578 & 1578 & 1578 & 1578 & 1578 & 1578 & 1578 & \\
\hline 1716 & 1712 & 1740 & 1708 & 1704 & 1721 & 1713 & $\mathrm{C}=\mathrm{O}$ stretch \\
\hline 1960 & 1960 & 1960 & 1960 & 1960 & 1960 & 1960 & \\
\hline 2109 & 2108 & 2109 & 2109 & 2109 & 2109 & 2108 & \\
\hline 2280 & 2264 & 2264 & 2263 & 2264 & 2263 & 2264 & \\
\hline 2378 & 2386 & 2379 & 2387 & 2383 & 2385 & 2385 & \\
\hline 2539 & 2540 & 2540 & 2542 & 2539 & 2540 & 2541 & \\
\hline 2906 & 2906 & 2906 & 2906 & 2906 & 2906 & 2906 & \\
\hline 2969 & 2969 & 2968 & 2969 & 2969 & 2969 & 2968 & $2800 \sim 3000 \mathrm{~cm}^{-1} \mathrm{C}-\mathrm{H}$ stretch \\
\hline 3059 & 3059 & 3059 & 3059 & 3059 & 3059 & 3059 & \\
\hline 3432 & 3431 & 3432 & 3432 & 3431 & 3432 & 3432 & \\
\hline 3554 & 3553 & 3554 & 3555 & 3548 & 3553 & 3552 & $3000 \sim 3700 \mathrm{~cm}^{-1} \mathrm{OH}$ stretch \\
\hline 3629 & 3629 & 3629 & 3631 & 3629 & 3629 & 3629 & \\
\hline
\end{tabular}

be seen that irradiated samples have a red shift [25] for the wavelengths in ultraviolet and near visible region. As expected, absorbance is seen to increase very steeply for wavelengths below a cutoff wavelength. There is also an absorption tail on the high wavelength side. It is clear from the results in Figure 4 that the absorbance graph for our PET samples shifts upwards (i.e., towards higher absorbance) monotonically with increasing $\gamma$-dose. However, Moura et al. [6] observed nonmonotonic behavior for LDPE samples, for irradiation doses 20,30 , and $65 \mathrm{kGy}$, and they called it inconsistent. Absorbance in the near-UV has been observed to be more sensitive to $\gamma$-irradiation in wavelength range 320 $370 \mathrm{~nm}$, out of 200 to $800 \mathrm{~nm}$ spectrum actually recorded. At an arbitrarily chosen wavelength of $335 \mathrm{~nm}$, for example, absorbance increases from the unirradiated value of 0.258 to 0.592 for $135 \mathrm{kGy}$, as detailed in Table 2 .

The change in absorption in this wavelength region is likely to be due to formation of unsaturated groups and presence of carbonyl and hydroxyl groups in the polymer due to the irradiation in air. The main effects of irradiation are chain scissions and crosslinking, accompanied by the formation of unsaturated products in the polymer chain. Free radicals produced in the polymer by the radiation can react with oxygen in air and form such groups. There are reports $[6,13,25]$ of such increase of carbonyl concentration due to $\gamma$-irradiation and also of formation of hydroxyl compounds.

\section{Conclusions}

FTIR absorption peak at $\sim 871 \mathrm{~cm}^{-1}$, representing out-ofplane $\mathrm{C}-\mathrm{H}$ bending mode of PET, disappears completely under the impact of initial dose (30 kGy) of gamma irradiation. No significant $\gamma$-irradiation-induced change in the region from $\sim 4000 \mathrm{~cm}^{-1}$ to $\sim 3000 \mathrm{~cm}^{-1}$ (attributed to $\mathrm{OH}$ bonding) tends to show that the hydroxyl group bonding configuration in the polymer chain remains almost intact under the influence of different doses of $\gamma$-irradiation. With initial $\gamma$-irradiation of $30 \mathrm{kGy}$ till $135 \mathrm{kGy}$, the $\mathrm{C}=\mathrm{C}$ bond stretching mode at $1246 \mathrm{~cm}^{-1}$ shifted to lower wave numbers in the range $1226-1150 \mathrm{~cm}^{-1}$. Further, $1303 \mathrm{~cm}^{-1}$ decreased 
TABLE 2: Measured absorbance of PET, at the wavelength $335 \mathrm{~nm}$, for different $\gamma$-doses.

\begin{tabular}{lccccccccc}
\hline$\gamma$-dose $(\mathrm{kGy})$ & 0 & 10 & 25 & 30 & 50 & 70 & 90 & 100 & 135 \\
\hline Absorbance & 0.258 & 0.274 & 0.310 & 0.315 & 0.375 & 0.412 & 0.456 & 0.511 & 0.592 \\
\hline
\end{tabular}

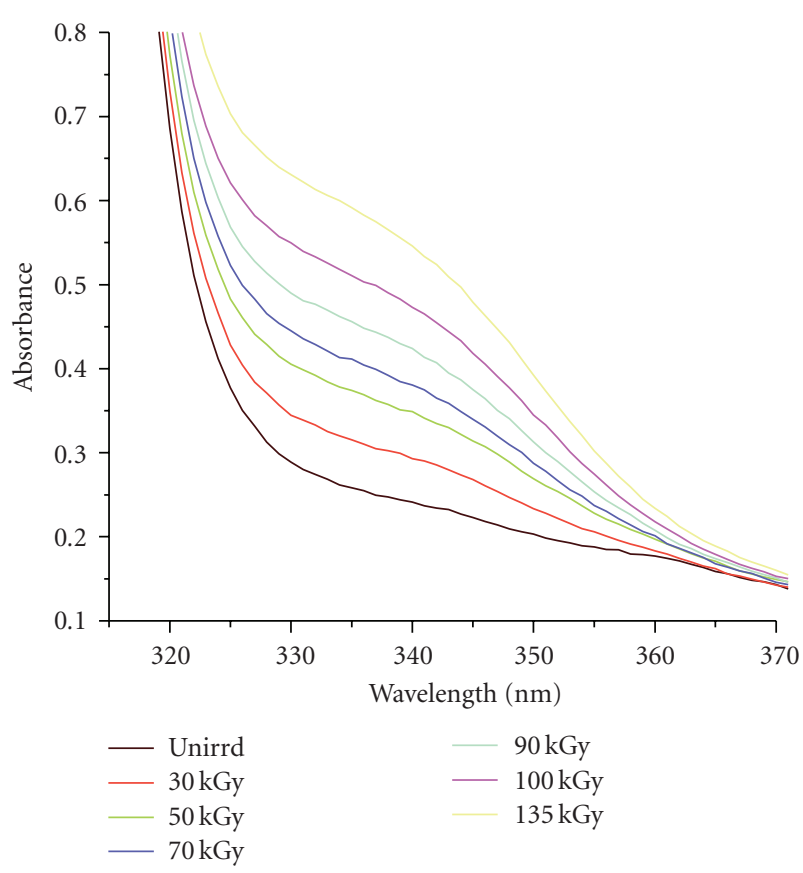

FIgURE 4: UV-Vis absorption spectra of PET-before and after gamma irradiation to different doses as indicated.

to $1260 \mathrm{~cm}^{-1}$ and varied till $1297 \mathrm{~cm}^{-1}$ indicated weakening of the respective carbon-carbon double bonding modes of vibration with increased dose of gamma irradiation. While on the other hand, the $\mathrm{C}-\mathrm{C}$ alkane $\left(-\mathrm{H}_{2} \mathrm{C}-\mathrm{CH}_{2}-\right)$ bond at $1328 \mathrm{~cm}^{-1}$ and $1390 \mathrm{~cm}^{-1}$ shows almost no change with increased dose of gamma irradiation. This could mean that chemical bond strength related to $\mathrm{C}-\mathrm{C}, \mathrm{C}-\mathrm{H}$, and $\mathrm{CH}_{2}$ remains invariant.

Crystalline structure in the present PET sample consists of (100) planes of atoms giving a XRD peak at $2 \theta=26^{\circ}$. Our XRD analysis has shown that gamma irradiation of PET samples has no influence on this crystalline structure, at least up to $135 \mathrm{kGy}$. This can be correlated to our FTIR observations. We see that $\mathrm{C}-\mathrm{O}-\mathrm{C}$ bond at $973 \mathrm{~cm}^{-1}$ and $\gamma-\left(\mathrm{CH}_{2}\right)$ transconfiguration bond at $850 \mathrm{~cm}^{-1}$ in the PET samples are hardly affected by different gamma radiation doses. As already discussed, these infrared absorption peaks are related to (100) crystallographic planes. So, XRD and FTIR results support each other in finding no loss of crystallinity.

In ultraviolet (UV) visible (VIS) spectroscopy, change of optical density or absorbance was detected even at the lowest dose ( $50 \mathrm{kGy}$ ) of $\gamma$-irradiation. UV barrier improves due to irradiation. Increase of absorbance with irradiation dose at any particular wavelength has been monotonic. Enhancement of optical absorption by $\gamma$-irradiation has been observed to be significant in wavelength range $320-370 \mathrm{~nm}$.

\section{Acknowledgments}

The authors thank the Director of UPTTI, Kanpur, Professor S. Basak (SINP), Professor D. K. Srivastava (VECC), and the Directors of VECC and SINP for encouragement and support. The FTIR spectroscopy was supported by the DST-FIST programme of the Government of India at the Department of Physics, Presidency College, Kolkata.

\section{References}

[1] J. Davenas, I. Stevenson, N. Celette et al., "Stability of polymers under ionising radiation: the many faces of radiation interactions with polymers," Nuclear Instruments and Methods in Physics Research. Section B, vol. 191, no. 1-4, pp. 653-661, 2002.

[2] A. Chapiro, "Chemical modifications in irradiated polymers," Nuclear Instruments and Methods in Physics Research. B, vol. 32, no. 1-4, pp. 111-114, 1988.

[3] A. Chapiro, "General consideration of the radiation chemistry of polymers," Nuclear Instruments and Methods in Physics Research, B, vol. 105, no. 1-4, pp. 5-7, 1995.

[4] T. Steckenreiter, E. Balanzat, H. Fuess, and C. Trautmann, "Chemical modifications of PET induced by swift heavy ions," Nuclear Instruments and Methods in Physics Research. Section $B$, vol. 131, no. 1-4, pp. 159-166, 1997.

[5] H. M. Abou Zeid, Z. I. Ali, T. M. Abdel Maksoud, and R. M. Khafagy, "Structure-property behavior of polyethylene exposed to different types of radiation," Journal of Applied Polymer Science, vol. 75, no. 2, pp. 179-200, 2000.

[6] E. A. B. Moura, A. V. Ortiz, H. Wiebeck, A. B. A. Paula, A. L. A. Silva, and L. G. A. Silva, "Effects of gamma radiation on commercial food packaging films - study of changes in UV/VIS spectra," Radiation Physics and Chemistry, vol. 71, pp. 199-202, 2004.

[7] G. Sadler, W. Chappas, and D. E. Pierce, "Evaluation of ebeam, $\gamma$ - and X-ray treatment on the chemistry and safety of polymers used with pre-packaged irradiated foods: a review," Food Additives and Contaminants, vol. 18, no. 6, pp. 475-501, 2001.

[8] R. Kumar, U. De, and R. Prasad, "Physical and chemical response of $70 \mathrm{MeV}$ carbon ion irradiated polyether sulphone polymer," Nuclear Instruments and Methods in Physics Research. Section B, vol. 248, no. 2, pp. 279-283, 2006.

[9] U. De,Journal of Polymer Engineering.

[10] K. C. Verma, M. Maitra, S. Tarafdar, T. R. Middya, and U. De, "Effect of $160 \mathrm{MeV}$ Ne-ion irradiation on polymer salt complex films containing laponite," Indian Journal of Physics, vol. 79, no. 7, pp. 769-772, 2005.

[11] A. Buttafava, G. Consolati, L. Di Landro, and M. Mariani, "Gamma irradiation effects on polyethylene terephthalate studied by positron annihilation lifetime spectroscopy," Polymer, vol. 43, pp. 7477-7481, 2002. 
[12] K. Dworecki, T. Hasegawa, K. Sudlitz, and S. Wasik, "Modification of electrical properties of polymer membranes by ion implantation," Nuclear Instruments and Methods in Physics Research Section B, vol. 166-167, pp. 646-649, 2000.

[13] Z. Zhu, C. Liu, Y. Sun et al., "Modification of polyethylene terephthalate under high-energy heavy ion irradiation," Nuclear Instruments and Methods in Physics Research, Section B, vol. 191, no. 1-4, pp. 723-727, 2002.

[14] B. C. Gilbert, Investigation of Molecular StructureSpectroscopic and Diffraction Methods, ELBS, Bell \& Hyman, London, UK, 2nd edition, 1984.

[15] F. W. Shen, H. A. McKellop, and R. Salovey, "Irradiation of chemically crosslinked ultrahigh molecular weight polyethylene," Journal of Polymer Science. Part B, vol. 34, no. 6, pp. 1063-1077, 1996.

[16] M. Day and D. M. Wiles, Journal of Applied Polymer Science, vol. 16, pp. 191-203, 1972.

[17] N. Iliskovic and M. Bravar, "Correlation of physico-chemical, mechanical and electrical properties of ultraviolet-degraded poly(ethylene terephthalate)," Polymer Degradation and Stability, vol. 15, no. 2, pp. 173-182, 1986.

[18] E. Balanzat, S. Bouffard, A. Le Moël, and N. Betz, "Physicochemical modifications induced in polymers by swift heavy ions," Nuclear Instruments and Methods in Physics Research. B, vol. 91, no. 1-4, pp. 140-145, 1994.

[19] E. Balanzat, N. Betz, and S. Bouffard, "Swift heavy ion modification of polymers," Nuclear Instruments and Methods in Physics Research, B, vol. 105, no. 1-4, pp. 46-54, 1995.

[20] N. Betz, A. Le Moel, E. Balanzat et al., "FTIR study of PVDF irradiated by means of swift heavy ions," Journal of Polymer Science. Part B, vol. 32, no. 8, pp. 1493-1502, 1994.

[21] G. Ungar, "Radiation effects in polyethylene and n-alkanes," Journal of Materials Science, vol. 16, no. 10, pp. 2635-2656, 1981.

[22] L. Maldelkem, in The Radiation Chemistry of Macromolecules, M. Dole, Ed., vol. 1, p. 287, Academic Press, New York, NY, USA, 1972.

[23] R. M. Silverstein, G. C. Bassler, and T. C. Morill, Spectrometric Identification of Organic Compounds, chapter 3, Wiley, New York, NY, USA, 1990.

[24] J. Davenas, X. L. Xu, G. Boiteux, and D. Sage, "Relation between structure and electronic properties of ion irradiated polymers," Nuclear Instruments and Methods in Physics Research. B, vol. 39, no. 1-4, pp. 754-763, 1989.

[25] I. Noda, A. W. Dowrey, and C. Marcott, Physical Properties of Polymers Handbook, AIP Press, New York, NY, USA, 1996.

[26] J. A. Dean, Handbook of Organic Chemistry, McGraw Hill, New York, NY, USA, 1987.

[27] T. Steckenreiter, E. Balanzat, H. Fuess, and C. Trautmann, "Pyrolytic effects induced by energetic ions in polymers," Nuclear Instruments and Methods in Physics Research. Section $B$, vol. 151, no. 1-4, pp. 161-168, 1999. 


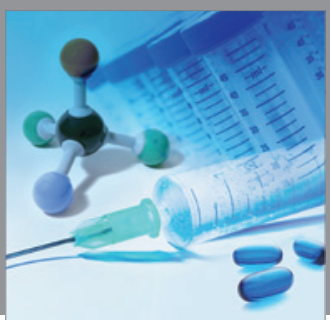

International Journal of

Medicinal Chemistry

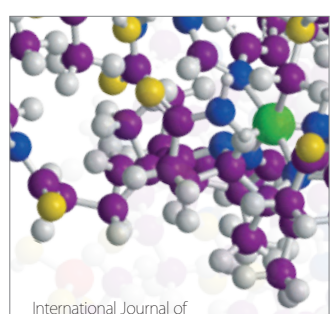

Carbohydrate Chemistry

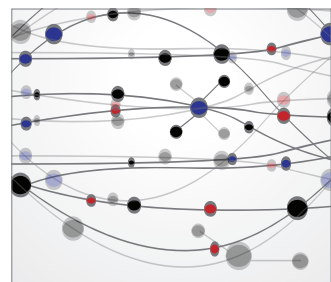

The Scientific World Journal
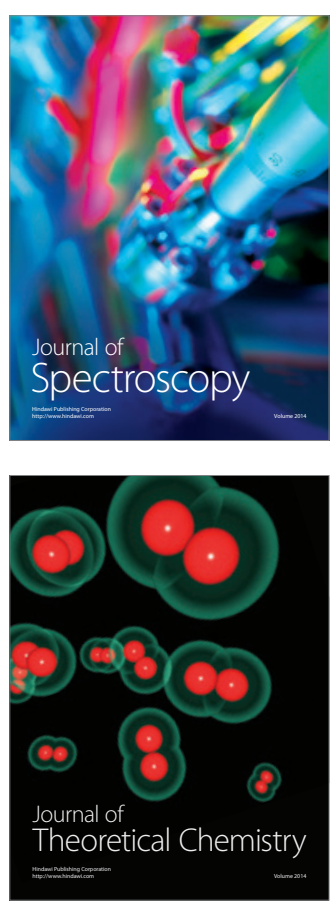
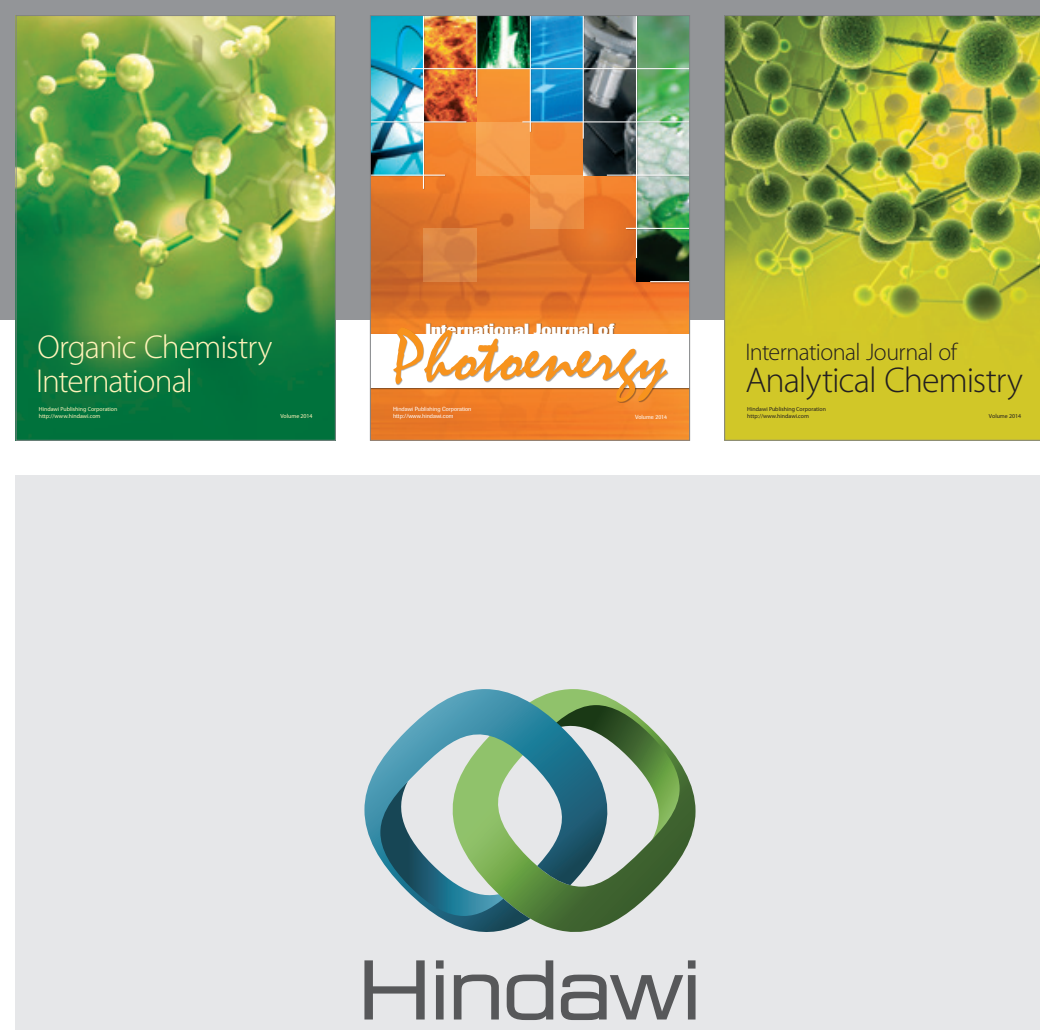

Submit your manuscripts at

http://www.hindawi.com
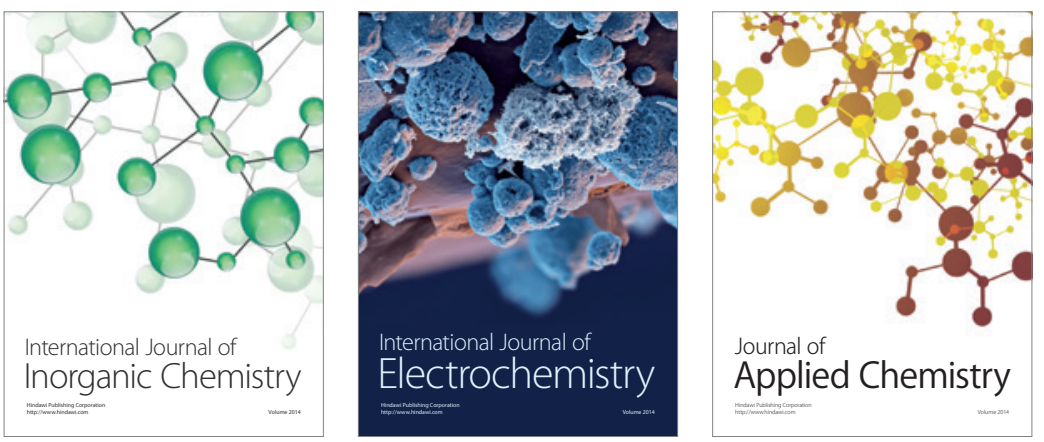

Journal of

Applied Chemistry
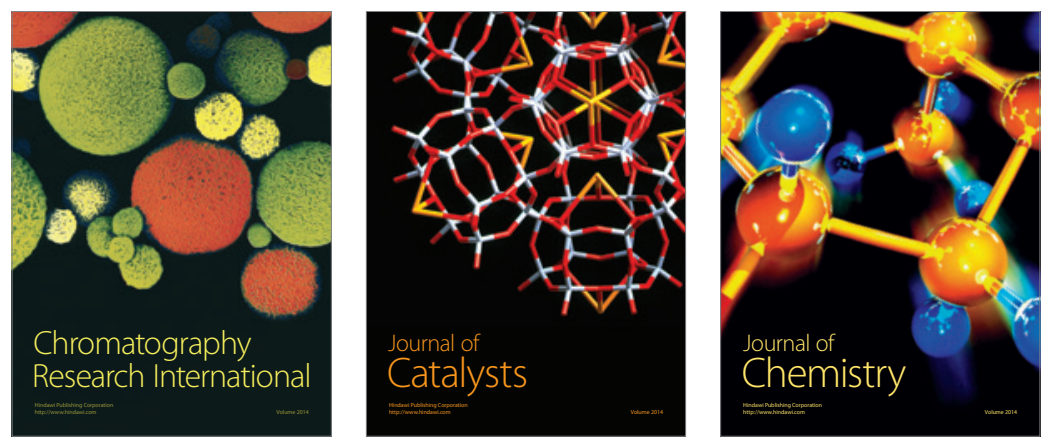
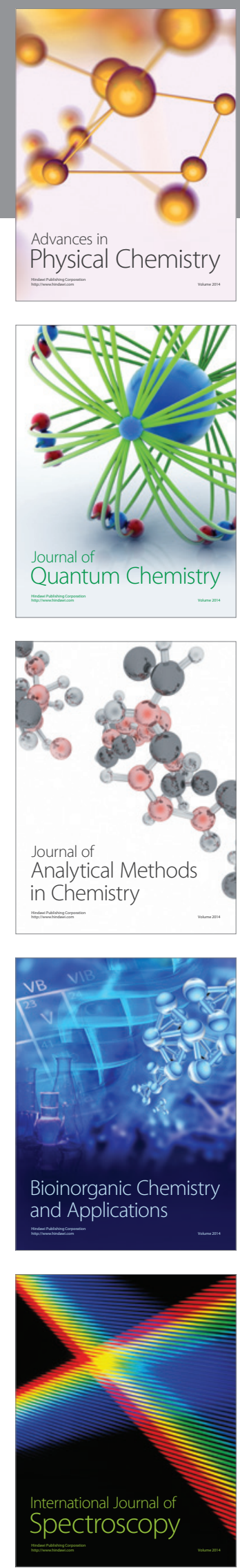